\title{
Synthesis of 1,3-Bis (N-Substitutedamidinothiocarbamido)-Thiocarbimides
}

\author{
SHELKE M.E. ${ }^{1}$
}

${ }^{1}$ Associate Professor in Chemistry, H.V.P.M. College of Engineering and Technology, HVPM Campus, Amravati (M.S.) 444605, INDIA ** e-mail meshelke@rediffmail.com

\begin{abstract}
Amidinothiocarbamides and their derivatives possess various pharmaceutical, industrial, medicinal and agricultural values ${ }^{1-4}$. Intraction of different thiocarbamides and substituted cyanamides were carried out to synthesised respective substituted thiocarbamides, bis-foramidino sulphide, amidinothiocarbamides (salt) and their derivatives. ${ }^{5-8}$ Amidinothiocarbamides and their derivatives were successfully cyclised into respective Hector's bases, thiadiazines, dithiazines, thiadiazolidines, s-triazines and pyrimidines by using different reagent and different reaction conditions. ${ }^{9-14}$ So it was thought interesting to synthesis yet new series of 1,3-bis ( $N$ substitutedamidinothiocarbamido)-thiocarbamides.(2) which may posses different pharmaceutical, industrial, medicinal, agricultural important which may be further cyclise to synthesis yet new series of 5 and 6 membered hetercyclic compounds. The structure of all these compounds were established on the basis of elemental analysis ,IR and PMR spectral data.
\end{abstract}

Keywords: Dicyandiamide, 1,3-Diformamidinothiocarbamide, amidinothio caramides, synthesis.

\section{Introduction}

Intraction of cyanamides with thiourea and substituted thiourea had been investigated in sufficient details. ${ }^{15}$ Dicyanamide has a cyanamide like structure therefore it appear interesting to carry out the reaction of dicyanamide with thiourea in presence of dil. hydrochloric acid in acetone medium to obtain 1,3-diformamidinothiocarbamide (1), having two amino groups at the terminal ends. Recently in these laboratories intraction of guanidine and different isothiocyanates were carried out at different ratios and at different reaction conditions to obtain different $\mathrm{N}$-substituted thioamidoguanidines ${ }^{16-17}$ and their derivatives.

As evident from the structure of 1,3-diformamidinothiocarbamide (1a) it posses two amino groups at terminal ends so, the intraction of (1a). were carried out with alkyl/arylisothiocyanate in 1:2 molar ratios in acetone medium to obtain yet new series of 1,3-bis ( $\mathrm{N}$-substitutedamidinothiocarbamido) thiocarbamides (2) respectively, which are hetherto not known. This reaction is akin to the reaction of parent guanidine and isothiocyanate in which related amidinothiocarbamides were formed. 


\section{Scheme}

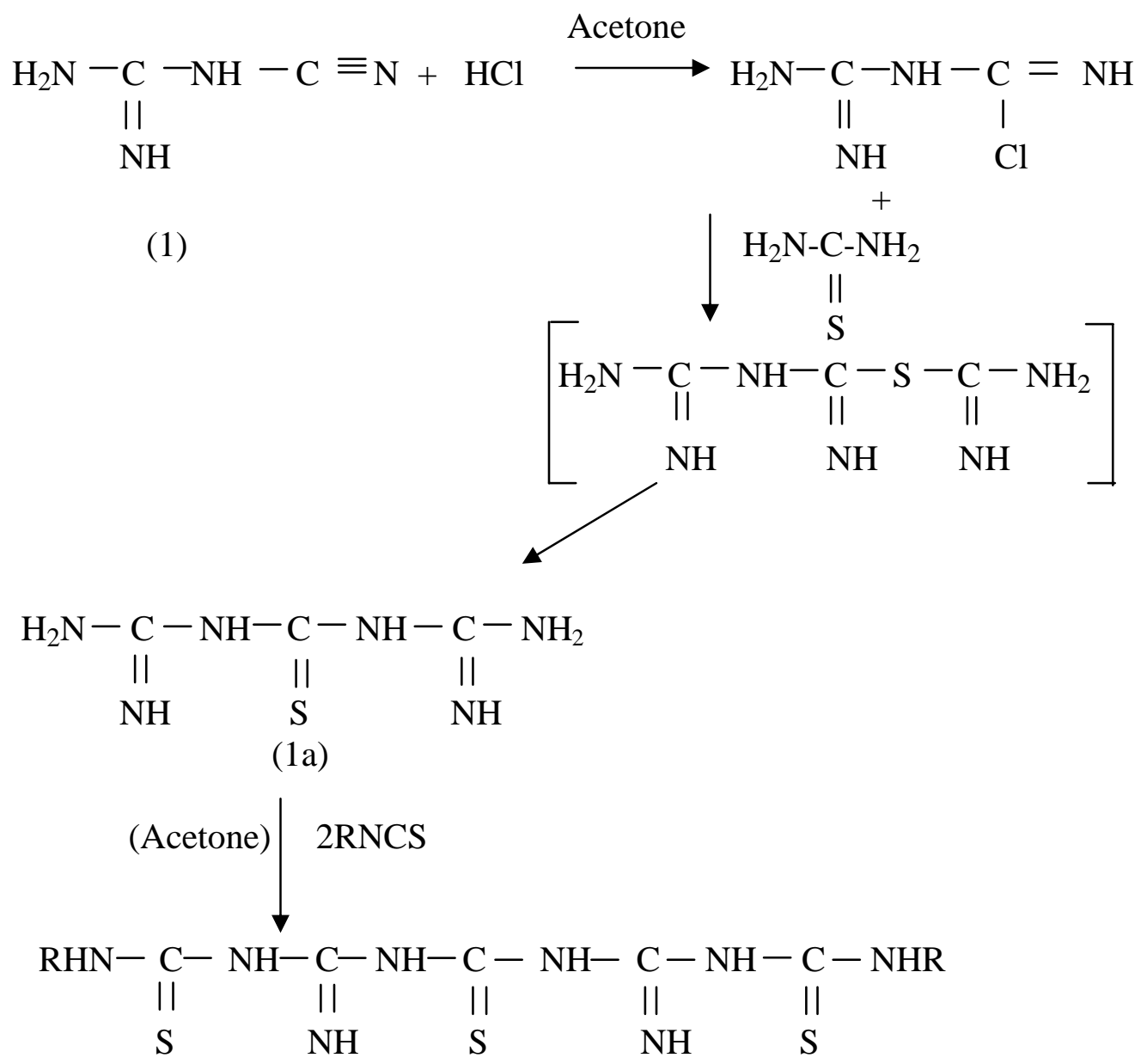

Where, $\mathbf{R}$ = phenyl, $p$-chlorophenyl, $p$-tolyl, ethyl, methyl, t-butyl

\section{Experimental}

All chemicals used were of analar grade. Substituted isothiocyanates were prepared according to literature method. ${ }^{18}$ Melting point of all synthesised compounds were determine in open capillary and uncorrected, IR spectra were recorded on Perkin-Elmer spectrometer in the range $4000-400^{\mathrm{cm}-1}$ in Nujol mull as $\mathrm{KBr}$ pellets.PMR spectra were recorded with TMS as internal standard using $\mathrm{CDCl}_{3}$ and DMSO- $d_{6}$. The purity of the compounds were checked on silica gel-G plates by TLC with layer thickness of $0.3 \mathrm{~mm}$. All compounds gave satisfactory $\mathrm{C}, \mathrm{H}, \mathrm{N}$ and $\mathrm{S}$ elemental analysis.

\section{1-3-Bis (N-phenylamidinothiocarbamido)thiocarbamide (2a):}

Mixture of (1a) $(0.01 \mathrm{~mol})$, phenylisothiocyanate $(0.02 \mathrm{~mol})$ and acetone $(50 \mathrm{ml})$ were refluxed on water bath for 12 h.in 1:2 molar ratio. The mixture was filtered and filtrate during distillation yielded the crystals of 3a.Yield $72 \%$; m.p. $270-72{ }^{0} \mathrm{c}$; IR spectra of compound shows $v(\mathrm{~N}-\mathrm{H}) 3471.3 \mathrm{~cm}^{-1}$, (C-H)(Ar) 
$3150.0 \mathrm{~cm}^{-1}, v(\mathrm{C}=\mathrm{N}) 1642.2 \mathrm{~cm}^{-1}, v(\mathrm{C}-\mathrm{N}) 1253.7 \mathrm{~cm}^{-1}, v(\mathrm{C}=\mathrm{S})$ grouping $1087.6 \mathrm{~cm}^{-1}, v(\mathrm{C}-\mathrm{S}) 721.7 \mathrm{~cm}^{-1}$, $v(\mathrm{C}=\mathrm{NH})$ grouping $1571.7 \mathrm{~cm}^{-1}$. The PMR spectra of compounds showed signals due to $\mathrm{N}-\mathrm{H}$ protons at $\delta$ 3.9-4.3 ppm , Ar-NH protons at $\delta$ 5.1-5.9 ppm, Ar-H protons at $\delta 6.3 \mathrm{ppm}$ and the signal at $\delta$ 3.1-3.2 ppm is due to moisture in DMSO- $d_{6}$. and $\delta 1.3-2.3 \mathrm{ppm}$ is due to DMSO.Found (Calc.) $\mathrm{C}=46.98 \%$ (47.44\%) H = 3.92\% (4.19\%) $\mathrm{N}=25.87 \%$ (26.05\%) S = 22.22\% (22.32\%).

Similarly others compounds (2b-2f) were synthesised by above mention method and enlisted in table-I

Table 1 Physical Data and Elemental Analysis of the Compounds (2a-F )

\begin{tabular}{|c|c|c|c|c|c|c|}
\hline \multirow[t]{2}{*}{ Compd. } & \multirow[t]{2}{*}{$\mathrm{R}$} & \multirow[t]{2}{*}{ m.f. } & \multirow[t]{2}{*}{ Yield } & \multirow[t]{2}{*}{$\begin{array}{l}\text { m.p. } \\
\left({ }^{0} \mathrm{C}\right)\end{array}$} & \multicolumn{2}{|c|}{$\begin{array}{l}\text { Elemental analysis found } \\
\text { (Calcd.)\% }\end{array}$} \\
\hline & & & & & $\mathbf{N}$ & S \\
\hline $2 a$ & phenyl & $\mathrm{C}_{17} \mathrm{H}_{18} \mathrm{~N}_{8} \mathrm{~S}_{3}$ & 72 & 270 & $25.87(26.05)$ & $22.22(22.32)$ \\
\hline $2 \mathbf{b}$ & p-chlorophenyl & $\mathrm{C}_{17} \mathrm{H}_{16} \mathrm{~N}_{8} \mathrm{~S}_{3} \mathrm{Cl}_{2}$ & 69 & 273 & 22.40 (22.49) & 19.24 (19.28) \\
\hline 2c & $p$-tolyl & $\mathrm{C}_{19} \mathrm{H}_{22} \mathrm{~N}_{8} \mathrm{~S}_{3}$ & 65 & 268 & $24.38(24.45)$ & $20.87(20.96)$ \\
\hline $2 d$ & ethyl & $\mathrm{C}_{9} \mathrm{H}_{18} \mathrm{~N}_{8} \mathrm{~S}_{3}$ & 74 & 242 & 33.44 (33.53) & $28.68(28.74)$ \\
\hline $2 e$ & methyl & $\mathrm{C}_{7} \mathrm{H}_{14} \mathrm{~N}_{8} \mathrm{~S}_{3}$ & 78 & 232 & $36.56(36.60)$ & 31.24 (31.37) \\
\hline $2 f$ & $t$-butyl & $\mathrm{C}_{13} \mathrm{H}_{26} \mathrm{~N}_{8} \mathrm{~S}_{3}$ & 72 & 259 & $28.62(28.72)$ & $24.53(24.61)$ \\
\hline
\end{tabular}

\section{Conclusion}

As outline in synthesis process, important novel thiocarbamides have been synthesized. All the structure of the above compounds was in good agreement with Spectral and Analytical data. and also shows novel biological activity.

\section{References}

1. $\quad$ Richard S, Robi S, Jackson P, J Am Chem Soc, 84, 1951, 589.

2. Jackson P, Joseph A, Podell T, J. Am. Chem Soc, 123, 1961,169

3. Elvino Fako, Shirley D, George Hitching, J Am. Chem Soc , 73, 1951, 3760

4. $\quad$ Birtwell S, Curd, F H S, Hendry J A , and Rose F L , J Chem Soc,1653, 1948.

5. $\quad$ Bamberger E , Ber dtsch.Chem Ges,16,1883,1460.

6. $\quad$ Rathke B, Ber dtsch Chem Ges,11, 1878,963.

7. Slotta K H and Tschesche R, Ber dtsch Chem Ges,62,1929,1398.

8. Joshua C P, J Sci.Industr Res, 21B,1962, 588.

9. $\quad$ Suresh K S, J Indian Chem Soc,37,1960,25,483

10. Joshua, C P, Verma V K and Suresh K S, Tetrahedron Lett,No 19, 1961,663 
11. Suresh K S, J Sci Res, Banaras Hindu Uni,IX 2,1958-59,94.

12. Srivastava P K, Indian J Chem,1,1963,354.

13. Pandeya S N, Ph.D.Thesis, Banaras Hindu Univ, 1965.

14. Tayade D T, Ph.D.Thesis, Amravati Univ, 1996.

15. Paranjape M G, J Indian Chem Soc, 1966, 42-45.

16. Shelke M E, Ph.D.Thesis, Amravati Univ, 2005

17. Shelke M E, Oriental Journal of Chemistry, Vol.22 (2) 2006, 277-280.

18. A. I. Vogel, Text book of practical organic chemistry including qualitative organic analysis, ELBS and Longman Greek and Co Ltd, 1954, 615. 